\title{
Regulation of sporulation in the yeast Saccharomyces cerevisiae
}

\author{
Iga Piekarska ${ }^{1}$, Joanna Rytka ${ }^{1}$ and Bozenna Rempola ${ }^{2 凶}$ \\ 1Department of Genetics, 2Department of Biophysics, Institute of Biochemistry and Biophysics, Polish Academy of Sciences, Warszawa, Poland
}

\begin{abstract}
Sporulation of the budding yeast Saccharomyces cerevisiae - equivalent to gametogenesis in higher organisms, is a complex differentiation program induced by starvation of cells for nitrogen and carbon. Such environmental conditions activate coordinated, sequential changes in gene expression leading to production of haploid, stress-resistant spores. Sporulation comprises two rounds of meiosis coupled with spore morphogenesis and is tightly controlled to ensure viable progeny. This review concerns the regulation of differentiation process by nutritional and transcriptional signals.
\end{abstract}

Keywords: sporulation, transcriptional regulation, meiosis, Saccharomyces cerevisiae

Received: 04 March, 2010; revised: 11 June, 2010; accepted: 08 September, 2010; available on-line: 15 September, 2010

\section{INTRODUCTION}

Cells of the yeast Saccharomyces cerevisiae, being nonmotile, depend on the availability of nutrients in their immediate surroundings. In the presence of adequate nutrient supply, regardless of their ploidy, the cells follow the mitotic cycle and proliferate by budding, giving rise to next generations of cells. In the event of complete depletion of essential nutrients, haploid cells enter a dormant stationary phase whereas diploid cells initiate a differentiation pathway called sporulation (reviewed in Kupiec et al., 1997). Two overlapping processes, meiosis and spore morphogenesis, make up the complex developmental program of sporulation (reviewed in Esposito \& Klapholz, 1981; Kupiec et al., 1997). Meiosis, reducing the ploidy of the cells, plays a central role in the sexual cycle. It is preceded by a prolonged meiS phase (premeiotic S phase) during which a single round of DNA replication occurs. In the next stage, meiotic prophase I, homologous chromosomes pair and exchange DNA through recombination. Following the recombination, the cells undergo two rounds of nuclear division, meiosis I (MI) and meiosis II (MII), leading to the formation of four haploid nuclei. Unlike higher eukaryotes, yeast cells undergo closed meiosis, meaning that the nucleus is surrounded by an intact nuclear envelope throughout the process. The second major event of sporulation is spore morphogenesis, when the four haploid nuclei are packaged into spores which are able to survive for a long time and which protect the genome from damage induced by chemical or physical stress (Smits et al., 2001). The process of spore morphogenesis requires two events. Firstly, prospore membranes (PSMs) are generated around the haploid nuclei to form prospores. Secondly, the newly formed prospores are surrounded by a protective, stress-resistant spore wall. In favorable condi- tions, each of the spores can germinate and enter the mitotic cell cycle. They can proliferate as haploids or may fuse with cells of the opposite mating type to regenerate diploid cells.

In this review we present state of the knowledge about regulation of sporulation in the yeast Saccharomyces cerevisiae, including mechanisms controlling repression of sporulation during vegetative growth and the nutritional and transcriptional signals determining sporulation events.

\section{SIGNALS CONTROLLING INITIATION OF SPORULATION IN YEAST}

Induction of the sporulation program is a complex and precisely controlled pathway. The cell's decision to initiate sporulation is regulated by genetic and nutritional signals which in $S$. cerevisiae are composed of: the type of cell, nutrient availability, and respiration (reviewed in Petronczki et al., 2003; Esposito, 2006). The genetic signal determining cell type comes from the mating type $(M A T)$ alleles. The ability to sporulate requires the presence of both $M A T \mathrm{a}$ and $M A T \alpha$ alleles. Thus, only diploid cells that express $M A T$ a and $M A T \alpha$, whose products form the a $1 / \alpha 2$ heterodimer, are able to sporulate. The decision to begin sporulation is also controlled by nutritional conditions. Starvation for nitrogen causes cell cycle arrest in the G1 phase, which is necessary for the initiation of sporulation (Hirschberg \& Simchen, 1977). The absence of a fermentable carbon source, such as glucose, is also required. Even low concentrations of glucose in the environment $(0.2-0.5 \%)$ repress sporulation initiation, also under conditions of nitrogen depletion (Honigberg \& Purnapatre, 2003). The third nutritional signal that controls the entry into sporulation is the presence of a non-fermentable carbon source, such as acetate, that can be metabolized by respiration. Respiration is required both as a signal for sporulation initiation and as a source providing energy for the subsequent processes (Jambhehar \& Amon, 2008). While a non-fermentable carbon source is needed only during the early stages of meiosis, prior to meiotic nuclear division, respiration is necessary throughout meiosis Jambhehar \& Amon, 2008). Therefore, cells must be respiratorily efficient to execute the developmental sporulation program.

\footnotetext{
e-mail: bozenna@ibb.waw.pl

Abbreviations: APC, anaphase-promoting complex; EMG, early meiotic gene; IRE, internal regulatory sequence; MAPK, mitogenactivated protein kinase; MMG, middle meiotic gene; MSE, middle sporulation element; NRE, negative regulatory element; PKA, protein kinase $A$; PSM, prospore membrane; SC, synaptonemal complex; SPB, spindle pole body; UAS, upstream activation sequence; UCS, upstream controlling sequence; URS, upstream repression sequence
} 


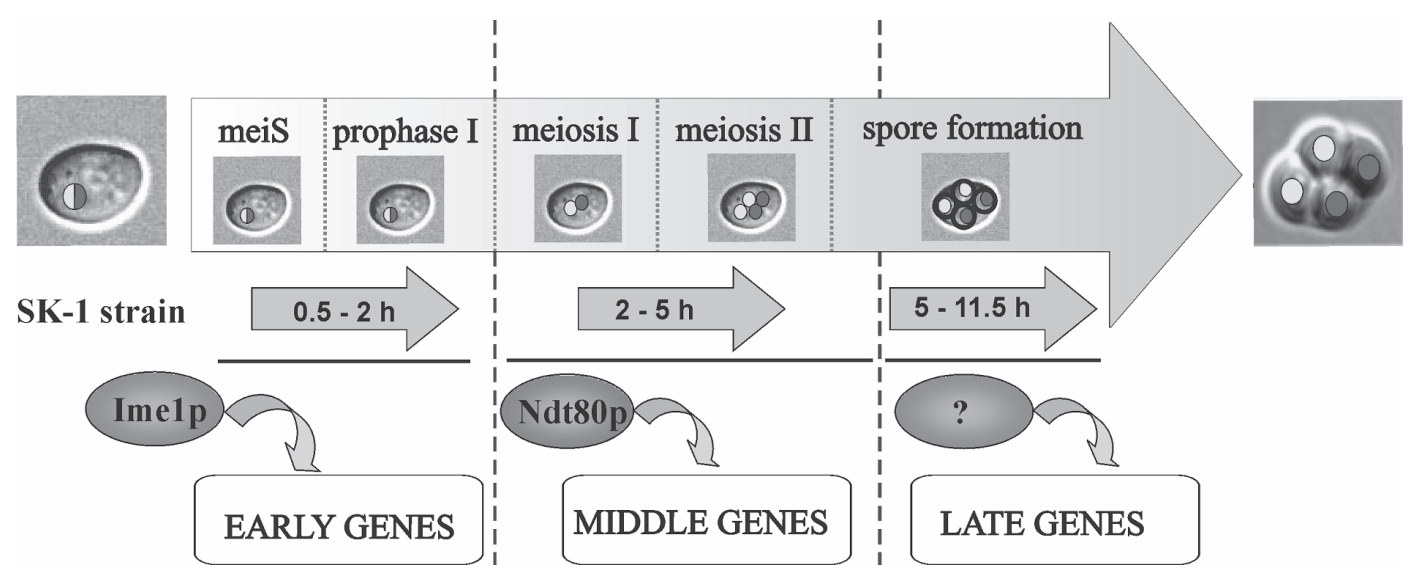

Figure 1. Transcriptional regulation of landmark sporulation events

During sporulation, three main classes of sporulation-specific genes - termed early, middle and late genes — are activated successively by several transcription factors. The master inducer of early genes is Ime1p, whereas Ndt80p activates the middle genes. The activator of late genes remains unknown. The figure presents timing of sporulation events in efficiently and fast sporulating SK-1 strain (After Mitchell, 1994 and Govin \& Berger, 2009).

The genetic and environmental signals activate a cascade of regulatory proteins resulting in coordinated, sequential changes in the expression of genes involved in various sporulation-specific processes. Microarray analyses have identified more than 1000 yeast genes that are transcriptionally regulated specifically during sporulation. About half of them are down-regulated and half up-regulated during different stages of sporulation (Chu et al., 1998; Primig et al., 2000). Based on the time of their induction, sporulation-specific genes have been classified into three main sequential groups: early, middle, and late genes (Mitchell, 1994; Fig. 1). The time at which a particular gene is expressed is closely correlated with its function. Immediately after the transfer of cells to sporulation medium not only expression of genes involved in sporulation is induced but also that of genes engaged in stress-response metabolic functions (i.e., response to nitrogen and carbon starvation, amino acid biosynthesis and mitochondrial functioning) (Primig et al., 2000). Early sporulation-specific genes are expressed at the beginning of meiotic prophase I, middle genes are transcribed at later stages of meiosis and during initiation of spore morphogenesis, while the expression of late genes is induced during spore formation. Members of each class of sporulation genes have common regulatory sequences within their promoters and are controlled by the same transcription factors; this determines their coexpression and ensures the correct order of activation of subsequent sets of sporulation-specific genes (Mitchell, 1994; Vershon \& Pierce, 2000). The set of early genes is induced by Ime1 (Inducer of Meiosis 1) (Kassir et al., 1988; Smith et al., 1993). The major regulator of middle genes is Ndt80p which also autoactivates its own expression (Chu et al., 1998; Chu \& Herskowitz, 1998; Pak \& Segall, 2002; Pierce et al., 2003). The factors required for the activation of the late genes remain unknown. Each group of genes involved in the sporulation process is repressed in vegetative cells as well as during the remaining parts of the sporulation process.

\section{REPRESSION OF SPORULATION PROGRAM DURING VEGETATIVE GROWTH}

The sporulation program is efficiently repressed in the presence of essential nutrients, when cells can divide mitotically. Furthermore, cells undergoing early stages of meiosis may return to vegetative growth if nutrients are provided. These cells complete early meiotic processes, such as replication and recombination, but then they switch to mitotic chromosome segregation and produce two diploid cells (Zenvirth et al., 1997; Friedlander et al., 2006). However, return to growth (RTG) is possible only before a specific stage of sporulation has been reached. This stage of irreversibility, called "commitment to meiosis" (Simchen et al., 1972, Friedlander et al., 2006), occurs after the events of prophase I but before the beginning of the first nuclear division. After this point, cells continue the sporulation process even if nutrients appear in the environment (reviewed in Friedlander et al., 2006; Simchen, 2009). Abandoning the sporulation program at later stages, when serious changes in chromatin structure, cell morphology and cell wall composition have occurred, could be lethal for the cell (Friedlander et al., 2006).

The expression of sporulation-specific genes during vegetative growth is prevented by several repressive mechanisms. These mechanisms are different for early, middle, and late genes. The central component controlling the repression of genes expressed early in the meiotic transcriptional program is a DNA binding protein, Ume6p (Unscheduled Meiotic Gene Expression 6) (Strich et al., 1994; Anderson et al., 1995; Steber et al., 1996). It associates with the Upstream Repression Sequence 1 (URS1) present in the promoters of most early genes and also in genes involved in metabolic responses to nutritional conditions (Strich et al., 1994; Anderson et al., 1995, Williams et al., 2002; Fig. 2A). Ume6p ensures that the cells respond to environmental changes by turning catabolic and anabolic genes on and off, respectively, and it also switches on the genes engaged in initiation and progression of meiosis (Williams et al., 2002). Ume6p activity involves the recruitment of two independent co-repressor complexes. One contains Sin3p and Rpd3p (Kadosh \& Struhl, 1998) and the other contains a subunit of a chromatin remodeling complex, Isw2p (Goldmark et al., 2000; Fazzio et al., 2001). The interaction between Ume6p and Sin $3 p$ - which forms a complex with the histone deacetylase Rpd3p - leads to local deacetylation of chromatin and to repression of transcription by blocking the functioning of activator proteins (Vershon \& Pierce, 2000). Independently of the 

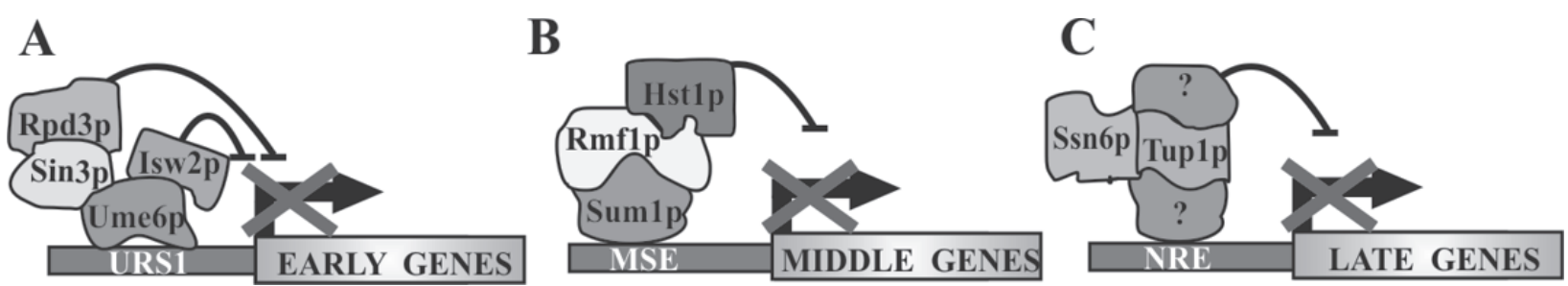

Figure 2. Repression of sporulation-specific genes during vegetative growth

(A) Early genes are repressed by Ume6p which binds to a specific site in promoters of early genes and recruits two complexes, Sin3pRpd3p histone deactylase and Isw2p chromatin remodeling complex. (B) Middle genes are repressed by Sum 1p which recruits histone deacetylase Hst1p via Rmf1p. (C) Repression of late genes is dependent on Ssn6p and Tup 1p, however, the exact mechanism of repression is not clear (After Vershon \& Pierce, 2000; Honigberg \& Purnapatre, 2003; Pnueli et al., 2004; Govin \& Berger, 2009).

Sin3p-Rpd3p complex, Ume6p recruits Isw2p, an ATPdependent chromatin-remodeling factor. Isw2p forms a complex required for the repression of early meiotic genes during mitotic growth and establishes inactive chromatin structure near the URS1 element (Goldmark et al., 2000).

The middle meiotic genes are repressed during vegetative growth and during early stages of the meiotic pathway by Sum1p (Xie et al., 1999), which binds to the Middle Sporulation Element (MSE) present in the promoters of most middle genes (Fig. 2B). Sum1p recruits the $\mathrm{NAD}^{+}$-dependent histone deacetylase Hst1p and thus promotes an inactive structure of chromatin and prevents transcription (Xie et al., 1999; Pierce et al., 2003; Weber et al., 2008). The interaction between Sum1p and Hst1p is dependent on Rfm1p which is essential for Sum1p-mediated repression (McCord et al., 2003).

Much less is known about the repression of late meiotic genes. The Ssn6p-Tup1p complex is required for repression of several sporulation genes, including late genes, but also some of the early genes (Friesen et al., 1997; Mizuno et al., 1998). The complex, in which Ssn6p likely acts as an adaptor while Tup1p contributes to repression activity (Smith \& Johnson, 2000), is recruited to target genes by unknown promoter-specific DNAbinding proteins (Fig. 2C). Multiple mechanisms including positioning of nucleosomes, recruitment of histone deacetylases, and interference with the transcriptional machinery are involved in Ssn6p-Tup1p-mediated repression (Zhang \& Reese, 2004).

Repression of sporulation in haploid cells largely depends on the zinc finger DNA-binding protein Rme1p (Regulator of Meiosis 1) (Kassir \& Simchen, 1976). The Rme1 protein blocks expression of the key regulator of sporulation, Ime1p (reviewed by Mitchell \& Herskow- itz, 1986; Kassir et al., 1988; Kupiec et al., 1997). The repressor binds directly to two sites within the IME1 promoter and modifies chromatin structure to prevent the binding of transcriptional activators (Schimizu et al., 1997). Rmelp also interacts with two subunits of the RNA polymerase II Mediator Complex, Rgr1p and $\operatorname{Sin} 4 \mathrm{p}$, which maintain a repressive chromatin structure at the IME1 promoter (Blumental-Perry et al., 2002). In haploid yeast cells and in artificially created diploids of inappropriate mating type, e.g., $M A T \alpha / M A T \alpha$, RME1 is expressed constitutively at a high level. In these cells, starvation leads to a further induction of RME1 transcription, which ensures that haploid cells do not initiate sporulation under any conditions (van Dyk et al., 2003).

\section{Ime1p, THE MASTER INDUCER OF SPORULATION}

The integration of the genetic and nutritional signals indicating that the cell is diploid and starved for both a fermentable carbon source and nitrogen causes expression of the transcription factor Ime1p. Ime1p, the key regulator of sporulation, switches on a transcriptional cascade of sporulation-specific genes. The promoter of IME1 is extremely large compared to other yeast genes $(2.1 \mathrm{~kb})$ and contains both positive and negative regulatory elements (Sagee et al., 1998). It is divided into four Upstream Controlling Sequences, named UCS1-4, which directly influence IME1 transcription (Fig. 3). UCS2 consists of seven elements: three Upstream Activation Sequences (UASv, UASrm, UASru), two Internal Regulatory Sequences (IREu and IREd), and two Upstream Repression Sequences (URSu and URSd). UCS1 and UCS2 respond to nutritional conditions while UCS3 and UCS4 are required for cell-type control.

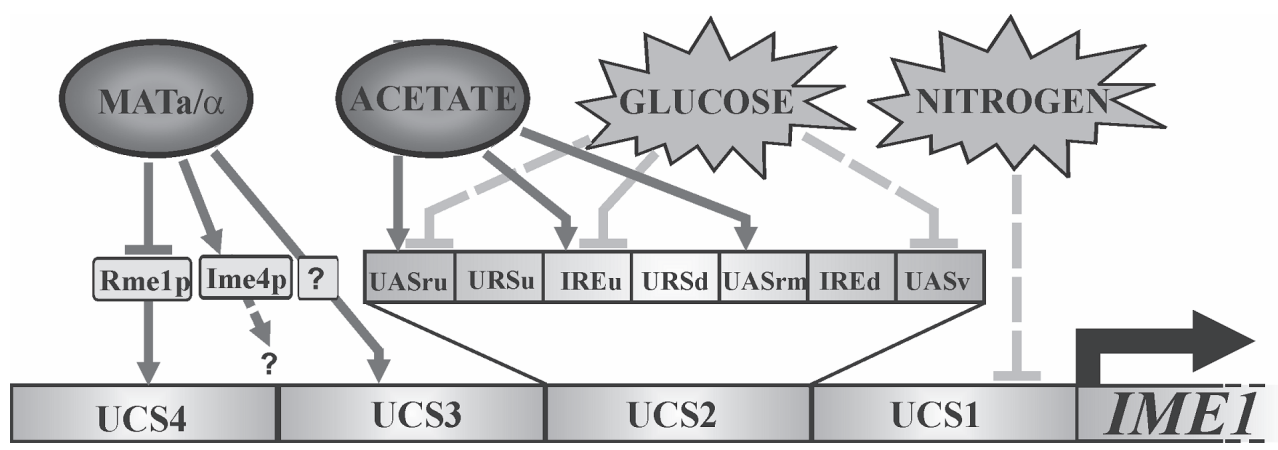

Figure 3. Regulation of IME1 transcription

IME1 promoter consists of positive and negative elements and is divided into four Upstream Control Sequences (UCS). UCS1 transmits the signal of nitrogen abundance which represses IME1 transcription. UCS2 responds to the type of carbon source. UCS3 and UCS4 transmit signals dependent on cell type and prevent sporulation in haploid cells (After Honigberg \& Purnapatre, 2003; Kassir et al., 2003; Govin \& Berger, 2009). 
The cell-type signal is transmitted to UCS4 via Rme1p (Covitz \& Mitchell, 1993), whereas the proteins that mediate the MAT signal via UCS3 are unknown. In haploid cells, Rme1p binds to an Rme1 Repressor Element (RRE) within UCS4 to repress IME1 transcription. In diploid $M A T a / M A T \alpha$ cells, the cell-type specific a1 and $\alpha 2$ proteins form a heterodimer which binds to regulatory sites in the promoter of RME1 to repress its transcription (Covitz et al., 1991; Herskovitz et al., 1992). The absence of Rme1p derepresses IME1 expression, allowing induction of sporulation. The Rmelp-dependent pathway is not the only mechanism whereby the a1/ $\alpha 2$ heterodimer stimulates IME1 and sporulation. The a1/ $\alpha 2$ proteins also regulate expression of the IME4 gene which encodes for putative RNA methyltransferase (Clancy et al., 2002) required for the induction of IME1 (Shah \& Clancy, 1992). Depending on the cell type, yeast express different IME4 transcripts (Hongay et al., 2006). Haploid cells produce non-coding, antisense IME4 RNA, because its promoter is stronger than the sense one (Govin \& Berger, 2009). In diploid cells, the antisense transcription is blocked by the a1 $/ \alpha 2$ heterodimer which binds downstream of the IME4 ORF to allow sense transcription. The sense transcript codes for the Ime4 protein which activates the expression of IME1. However, the region in the IME1 promoter which responds to Ime4p and the mechanism of Ime1 activation by Ime4p are unknown.

The nutritional signals that regulate IME1 expression are substantially more complex than the regulation by cell type. Several of the IME1 promoter elements func- tion as activator and repressor sites sensitive to the availability of nitrogen and to the type of carbon source, such as acetate or glucose. Nitrogen abundance has a repressive effect on IME1 transcription; this signal is sensed by UCS1 (Matsumoto et al., 1983; Fig. 3). Glucose represses IME1 expression via three distinct elements of UCS2: UASru, UASv and IREu, whereas acetate activates IME1 transcription via UASru, UASrm and IREu (reviewed in Kassir et al., 2003).

\section{SIGNALING PATHWAYS REGULATING THE SPORULATION PROGRAM}

Nutritional signals are mediated by nutrient-sensing pathways integrated into a signaling network which regulates entry into and progression through the sporulation program. This network is composed of the Tor $2 p$ pathway and the glucose repression, alkaline-sensing, RAS, and cAMP-PKA pathways (rewieved in Honigberg \& Purnapatre, 2003; Kassir et al., 2003; Fig. 4).

The Tor $2 \mathrm{p}$ pathway, involved in the cellular response to nitrogen concentration, is inactivated through nitrogen deprivation. This causes changes in cell metabolism which result in G1 phase arrest. When G1 arrest occurs, the level of Cln/Cdk activity (a G1 cyclin and cell cycle cyclin-dependent kinase, respectively) declines, allowing the initiation of meiosis (Colomina et al., 1999). A high level of $\mathrm{Cln} / \mathrm{Cdk}$ activity blocks IME1 expression and Ime1p import into the nucleus, preventing the activation of early sporulation-specific genes (Zaman et al., 2008).

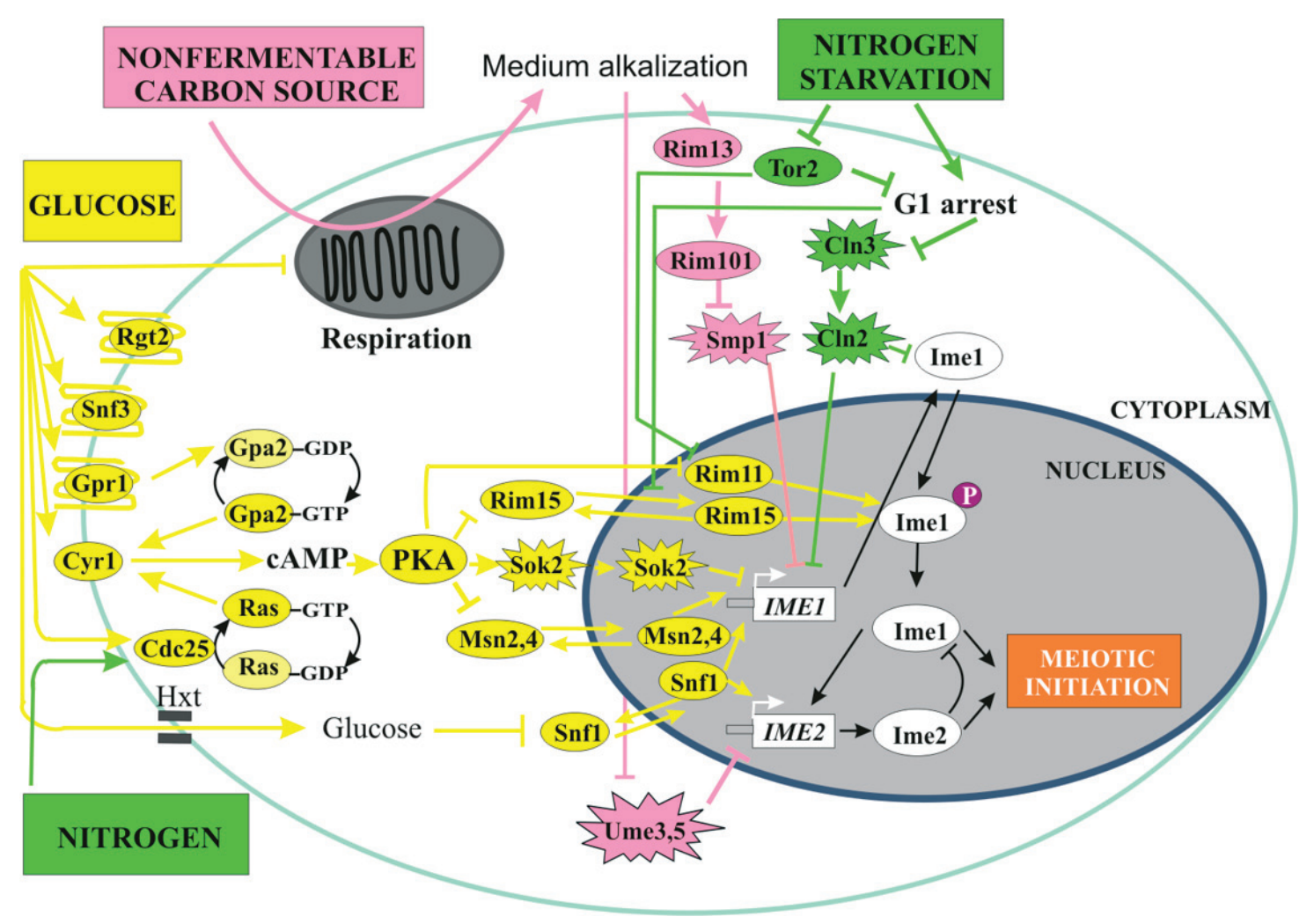

Figure 4. Signaling pathways that regulate sporulation

Nutritional signals are transmitted by nutrient signaling pathways such as glucose repression, alkaline-sensing, Tor2p, RAS and cAMPPKA, which regulate expression of the master activator of sporulation Ime1p. Glucose represses IME1 transcription by activation of Sok2p repressor and by inhibition of Msn2p-Msn4p and Snf1p activators as well as by inhibition of respiration - a process indispensable for media alkalization, which inhibits Swm1 p repressor. Moreover, glucose and nitrogen repress Rim11p and Rim15p kinases needed for full activation of Ime1p. Nutrient starvation decreases Cln/Cdk activity, allowing IME1 expression and Ime1p transport to the nucleus and, in consequence, activation of IME2 and other early sporulation genes (After Honigberg \& Purnapatre, 2003; Santangelo, 2006; Zaman et al., 2008). 
The cell's response to glucose and nitrogen depends strongly on RAS and cAMP-dependent protein kinase A (PKA) (Honigberg \& Purnapatre, 2003; McDonald et al., 2009). The nitrogen signal is transmitted to the UCS1 element within the IME1 promoter through Cdc25p - a regulator of the RAS/adenylate cyclase pathway - causing repression of UCS1 activity (Matsumoto et al., 1983). Glucose regulates sporulation at three different steps: it controls expression of IME1 and IME2 and manages the entry into later sporulation events (Honigberg \& Lee, 1998). Extracellular-glucose sensing depends on the transmembrane proteins Rgt2, Snf3, and Gpr1, and on the Hxt hexose transporters, whereas intracellular sensing occurs through the Gpa2p pathway which works in parallel with the RAS pathway to activate PKA (Santangelo, 2006). Activation of PKA, which depends on glucose and other signals, results in repression of IME1 transcription. PKA phosphorylates the stress response factors Msn2p and Msn4p, thus repressing their function as transcriptional activators of stress-response genes (Garreau et al., 2000). Some of these genes are required for IME1 induction (Honigberg \& Purnapatre, 2003). Moreover, Msn2p-Msn4p induces transcription of IME1 directly (Sagee et al., 1998). PKA also regulates the activity of Sok2p which, when phosporylated, represses the transcription of IME1 (Shenhar \& Kassir, 2001). Furthermore, glucose and nitrogen signals negatively regulate the kinases Rim15p and Rim11p which phosphorylate Ime1p and promote the induction of sporulation (RubinBejerano et al., 2004; Zaman et al., 2008). Glucose represses the expression of RIM15 whereas the PKA pathway inhibits the activity of Rim $15 p$ and Rim11p through inhibitory phosphorylation. Glucose is also sensed in a PKA-independent manner by the Snf1p kinase. Its activity is required for IME1 and IME2 expression (Honigberg \& Lee, 1998) and is inhibited by high levels of glucose. Thus, glucose and nitrogen control IME1 expression both by inactivating an activator and by activating a repressor of this gene. In addition, glucose and nitrogen control Ime1p activity also at a post-transcriptional level. Progression through the sporulation program requires that the sporulation-initiating nutritional signals remain present.

The presence of a non-fermentable carbon source, which is metabolized respiratorily, leads to the production of $\mathrm{CO}_{2}$, which is partially dissolved in the medium in the form of bicarbonate ion $\left(\mathrm{HCO}_{3}{ }^{-}\right)$. Hence, the acetate ions in the medium are partially replaced by $\mathrm{HCO}_{3}^{-}$, which results in accumulation of bicarbonate and in consequence alkalization of the medium (Hay- ashi et al., 1998). The high external $\mathrm{pH}$ induces the alkaline-sensing pathway that includes cell surface factors and the transcriptional regulator Rim101p. Activation of Rim101p depends on its proteolytic cleavage by the Rim13p protease (Lamb \& Mitchell, 2003). The active form of Rim101p represses Smp1p which inhibits IME1 expression probably by binding to the UASrm site in the IME1 promoter (Zaman et al., 2008). Additionally, medium alkalization causes degradation of the Ume3p-Ume5p cyclin-kinase complex. This degradation is required for efficient induction of IME2 expression (Cooper \& Strich, 2002). Thus, respiratory metabolization of a nonfermentable carbon source, leading to medium alkalization, promotes sporulation through expression of both IME1 and IME2.

In summary, the proteins that regulate the action of factors required for the initiation of sporulation are controlled by more than one pathway or factor (Honigberg \& Purnapatre, 2003). Furthermore, one pathway can regulate the transcription of a gene whose product can then be controlled on a post-translational level by another pathway.

\section{GENES EXPRESSED EARLY IN SPORULATION PROGRAM}

After transfer of the cells to sporulation conditions, more than 200 sporulation-specific genes are expressed (Chu et al., 1998; Vershon \& Pierce, 2000). This set of genes is termed early meiotic/sporulation genes (EMGs). The proteins they encode are involved in the earliest stages of sporulation, such as premeiotic DNA replication and prophase I events. Prophase I is composed of four substages. During leptotene, telomeres migrate to the spindle pole bodies (SPBs) - a yeast equivalent of the microtubule organization center — and form the telomere bouquet. Next, homologous chromosomes pair and become synapsed along their entire length by proteinaceous synaptonemal complexes (SCs) assembled during zygotene. At pachytene, recombination is completed, and at diplotene, the SCs are dismantled, however, homologous chromosomes remain joined by chiasmata which form as a result of recombination events. Exit from pachytene is also connected with separation of SPBs and modification of kinetochores. The SPBs, which duplicate before meiosis I, at a time close to the onset of premeiotic DNA replication, separate and migrate to opposite sites of the nucleus at diplotene. The modification of kinetochores causes sister kinetochores to orient toward the same SPB in meiosis I. After these
A

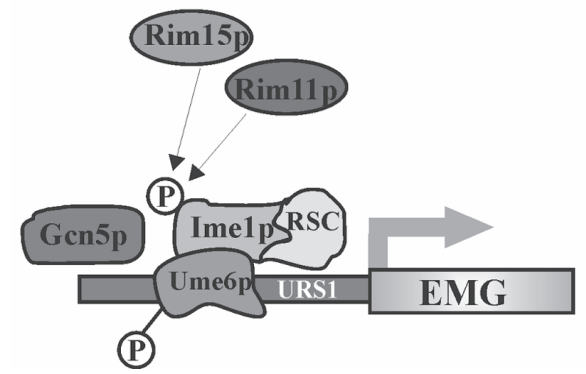

B

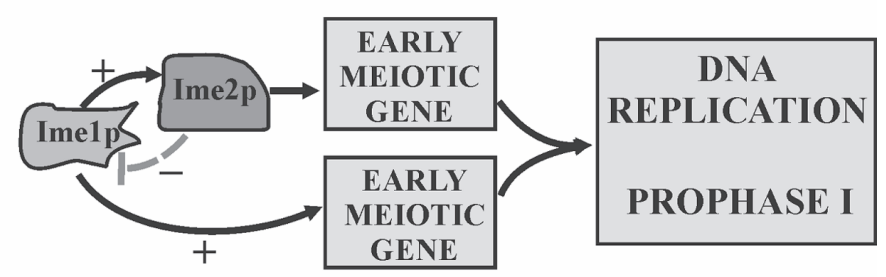

Ime1p-DEPENDENT PATHWAY

Figure 5. Transcriptional regulation of early sporulation genes

(A) Ime1p, a transcriptional activator of early genes, binds to specific elements in promoters of early genes and induces their expression. Efficient activation of EMGs requires chromatin-remodeling complex RSC, histone acetyltransferase Gcn5p, and kinases Rim11p, Rim15p and Mck1p (After Inai et al., 2007 Govin \& Berger, 2009). (B) Ime1p activates EMG expression by two different pathways: Ime1p-dependent and Ime2p-dependent (After Mitchell, 1994; Guttmann-Raviv et al., 2002). 
processes have been completed, the cell enters the first meiotic division.

Based on the time of their expression, three classes of early genes have been distinguished: early I (62 genes), early II (47 genes), and early-middle (95 genes) (Chu et al., 1998; Vershon \& Pierce, 2000). Expression of the early II and early-middle gene sets is slightly delayed compared with the early I set. Additionally, the early-middle genes differ from the early I and II classes in that they are re-induced parallel to the induction of middle genes (Chu et al., 1998). Many of the early I and II genes are implicated in meiotic homologous chromosome centromere pairing, synapsis, recombination, and pachytene checkpoint functions, whereas early middle genes play roles in spindle pole body dynamics or chromatid behavior (Chu et al., 1998).

Expression of early meiotic genes (EMGs) is initiated by Ime1p (Kassir et al., 1988). Most EMG promoters have a common conserved Upstream Repression Sequence (URS1) element which serves as a repressor site during vegetative growth and as an activator site under sporulation conditions. Ime1p activates the expression of early genes by associating with URS1 via Ume6p, a DNA binding repressor (Strich et al., 1994; Fig. 5A). Efficient induction of EMG transcription additionally requires the chromatin-remodeling machinery such as the chromatin-remodeling complex RSC or Gcn5p, a histone acetyltransferase which regulates chromatin organization around the URS1 element (Inai et al., 2007). The chromatin-remodeling complex untangles the repressive chromatin structure maintained by $\operatorname{Sin} 3 \mathrm{p}-\mathrm{Rpd} 3 \mathrm{p}$ and the Isw $2 p$ complex during vegetative growth. Gcn5p changes the local chromatin structure and alters nucleosome positioning to allow gene expression (Burgess et al., 1999). Gcn5p may also cause modification of the higher chromatin structure, thus facilitating the binding of Ime1p independently of nucleosome positioning (Inai et al., 2007).

URS1 is a relatively weak activator sequence, and therefore other activator elements augment the level of early gene expression (Vershon \& Pierce, 2000). Many EMGs have activator segments such as $\mathrm{T}_{4} \mathrm{C}$ or $\mathrm{UAS}_{\mathrm{H}}$, which lie upstream of URS1. Also an Abf1p-dependent regulatory element which binds the general transcriptional activator has been identified in several EMG promoters (Schlecht et al., 2008).

The expression of most early genes requires two different pathways, one Ime1p- and the other Ime2p-dependent (Fig. 5B). However, Ime1p is indirectly necessary for both pathways since IME2 expression is positively regulated by Ime1p (Yoshida et al., 1990). Ime1p and Ime2p switch on many of the same genes. Despite the common targets, stimulation of EMG transcription by the Ime1p and Ime2p pathways occurs through different regulatory sites (Mitchell, 1994). Amplification of Ime1p activity by Ime2p action likely ensures a balanced expression of early meiotic genes engaged in the earliest stages of sporulation (Mitchell, 1994).

The Ime1-dependent pathway is related to Ume6p, the kinases Rim11p and Rim15p, and potentially to other kinases such as Mck1p (Xiao \& Mitchell, 2000). Rim11p and Rim15p phosphorylate Ime1p and Ume6p and stabilize their association (Vidan \& Mitchell, 1997; Xiao \& Mitchell, 2000). Several previous reports have indicated that Ume6p can act both as a repressor and an activator of genes expressed early in the transcriptional sporulation program, and its conversion from transcriptional repressor to activator is related to its association with the
Ime1p inducer (Bowdish et al., 1995; Rubin-Bejerano et al., 1996; Washburn \& Esposito, 2001). However, recent literature data support an alternative mechanism suggesting that Ume6p is degraded in cells transferred from growth conditions to sporulation conditions. Its elimination requires entry into sporulation and is connected with a transient interaction with Ime1p (Mallory et al., 2007).

In the Ime2p-dependent pathway, Ime1p plays only an indirect role by stimulating IME2 expression. Ime2p, a CDK-like protein kinase which has autophosphorylation activity, controls the G1-S transition by decreasing the level of Sic1p, an inhibitor of the Clb-Cdc28 kinase (a Btype cyclin and the catalytic subunit of the main cell cycle cyclin-dependent kinase, respectively) (Benjamin et al., 2003). Degradation of Siclp results in the activation of the Cdc28-Clb5,6 complex which promotes the meiotic G1-S phase transition and premeiotic DNA replication (Mitchell, 1994; Vershon \& Pierce, 2000; Kassir et al., 2003; Neiman, 2005). Ime2p not only induces early gene expression but also promotes the $\mathrm{S}-\mathrm{M}$ phase transition by phosphorylation and activation of Ndt80p, a transcriptional activator of middle sporulation genes (Benjamin et al., 2003), and controls chromosome segregation by regulating the activity of the anaphase-promoting complex/cyclosome (APC/C) (Bolte et al., 2002). Later in the sporulation program, Ime2p terminates EMG expression by phosporylation of Ime1p which targets it for degradation (Guttmann-Raviv et al., 2002). Thus, IME1 expression occurs in a narrow window relative to Ime2p, and Ime $2 p$ plays multiple roles in promoting progression through sporulation.

\section{GENES EXPRESSED IN THE MIDDLE MEIOTIC PHASE}

When cells exit meiotic prophase I, the early meiotic genes are switched off and transcription of about 160 middle meiotic/sporulation genes (MMGs) is induced (Chu et al., 1998; Vershon \& Pierce, 2000). Proteins encoded by MMGs are required for the prophase I to metaphase I transition, for meiotic division and for the initiation of spore morphogenesis. Exit from prophase I is dependent on the kinase activity of the cell cycle regulator Cdc28p, which is promoted by the cyclins $\mathrm{Cln} 1 \mathrm{p}$, $\mathrm{Cln} 3 \mathrm{p}, \mathrm{C} \ln 4 \mathrm{p}, \mathrm{C} \ln 5 \mathrm{p}$, and $\mathrm{Cln} 6 \mathrm{p}$ (Chu \& Herskowitz, 1998). Then, two successive rounds of meiotic division occur. During the first, "reductive" division, named meiosis I, homologous chromosomes are pulled to the opposite spindle pole bodies by microtubules, which are attached to the kinetochores. Sister chromatid centromeres remain linked by a multiprotein cohesion complex and their kinetochores are attached to microtubules emanating from the same SPB. This type of attachment is termed mono-orientation or syntelic attachment. The second, "equational" division, named meiosis II, resembles a mitotic division although, unlike mitosis and meiosis I, it is not preceded by a round of DNA replication. The cohesion complex, which holds sister centromeres together, is destructed, and sister chromatids segregate to opposite SPBs because their kinetochores are attached to microtubules formed by two different SPBs. This is termed bi-orientation of sister chromatids or amphitelic attachment.

The meiotic division is coupled to spore morphogenesis, resulting in the encapsulation of each of the four haploid nuclei into stress-resistant ascospores. Spore morphogenesis comprises prospore membrane formation 
and spore wall maturation, and it is initiated during the second meiotic division. In early meiosis II, the newly duplicated SPBs undergo modifications and their cytoplasmic surfaces — the meiotic plaques - become sites of prospore membrane formation (rewieved in MorenoBorchart \& Knop, 2003; Neiman, 2005). The meiotic plaques recruit vesicles carrying cargo for building of the prospore membranes (PSMs). The vesicles fuse to form the initial prospore membrane caps. In later stages of sporulation, PSMs encapsulate the haploid nuclei and four prospores are formed.

Expression of the middle sporulation-specific genes is activated by the global activator Ndt80p that also positively regulates its own expression (Chu et al., 1998; Chu \& Herskowitz, 1998; Pak \& Segall, 2002; Pierce et al., 2003). This transcription factor, which is expressed earlier than other MMGs, recognizes and binds to the conserved middle sporulation elements (MSEs) that are present upstream of $70 \%$ of the middle genes (Chu et al., 1998; Vershon \& Pierce, 2000). The MSE sites in different middle genes function differently. Some MSEs play a double role: during sporulation they function as activator sites whereas during vegetative growth, and also in early stages of sporulation, as repressor sites. In other genes of the middle class, the MSEs are strong activator elements but weak repressor sites (Chu et al., 1998; Vershon et al., 2000; Kassir et al., 2003). It currently remains unclear why different MSEs display different activities. On the other hand, $30 \%$ of the middle sporulation genes lack MSE sites (Chu et al., 1998, Chu \& Herskowitz, 1998). However, their induction is probably still dependent on Ndt80p: either Ndt80p binds to non-canonical elements in MMG promoters or it activates other factors that promote expression of these genes (Chu et al., 1998; Vershon \& Pierce, 2000). Although the Ndt80p factor plays an essential role in the activation of middle sporulation genes, the expression of some MMGs may be regulated independently of Ndt80p (Chu et al., 1998). Some genes in the MMG class also contain other positive regulatory elements such as URS1 or an Abf1p-binding site (ABS), which increase the expression level (Vershon \& Pierce, 2000; Kassir et al., 2003).
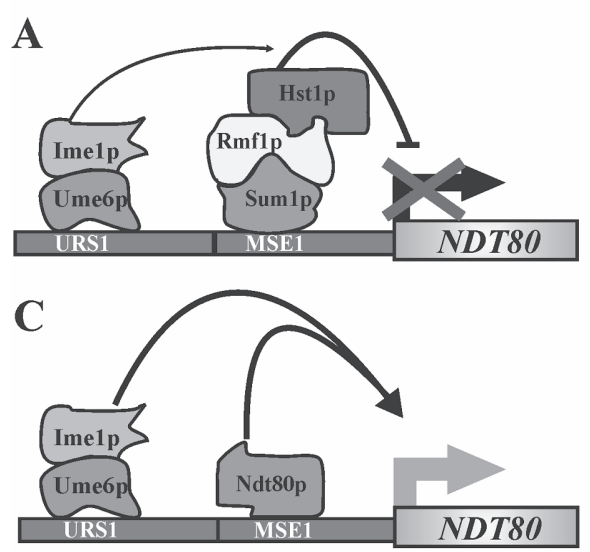

Expression of the transcriptional activator of middle genes Ndt80p is induced by Ime1p and Ime2p (Chu \& Herskowitz, 1998; Hepworth et al., 1998; Pak \& Segall, 2002). The promoter of NDT80 contains two URS sites, termed URS1 and URS2, and also two MSE sequences called MSE1 and MSE2 (Pak \& Segall, 2002). URS1 functions either as a repressor site (under growth conditions) or as an activator site (under sporulation conditions), whereas URS2 functions only as an activator-binding site. The MSEs, similarly to URSs, contribute either to both repression and activation of NDT80, depending on the environmental conditions (MSE1) or only to its activation (MSE2) (Pak \& Segall, 2002). Thus, in vegetative cells, transcription of NDT80 is repressed by both Sum1p, that binds to MSE1 sites, and by Ume6p, which binds to URS1 sites (Fig. 6A). In sporulation conditions, when Ime1p promotes transcription of early meiotic genes by transient association with Ume6p, activation of NDT80 by Ime1p-Ume6p is initially prevented by the presence of Sum1p at the MSE1 site (Fig. 6B). Then, the repressor activity of Sum1p is inhibited by newly formed Ime2p allowing Ime1p to promote low levels of NDT80 expression. The newly synthesized Ndt80p competes with Sum1p and activates its own expression by binding to the MSE1 site, leading to high NDT80 transcription (Fig. 6C). Full activity of Ndt80p promotes expression of genes coding for B-type cyclins (Clb1, Clb3-Clb6) and proteins required for the meiotic division and for the initiation of spore formation (Chu \& Herskowitz, 1998; Hepworth et al., 1998; Pak \& Segall, 2002; Fig. 6D).

\section{GENES EXPRESSED LATE IN MEIOSIS}

Late meiotic/sporulation genes (LMGs), have been divided into two classes, based on the timing of their expression (Chu et al., 1998; Vershon \& Pierce, 2000). The first group, called middle-late genes, consists of about 61 genes that are required for spore formation. Some genes involved in mitochondrial function or vacuolar morphogenesis and inheritance are also initiated during the middle-late stages of sporulation (Chu et al., 1998). The sec-

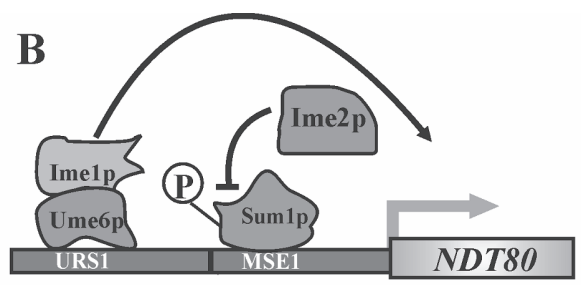

$\mathbf{D}$

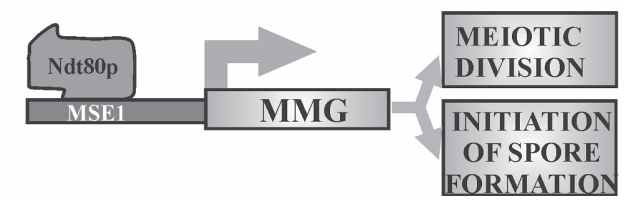

Figure 6. Transcriptional regulation of middle sporulation genes

(A) In early stages of sporulation, transcriptional activator Ime1p binds to specific sites in the promoter of NDT80, activator of middle genes. However, NDT80 transcription is repressed by Sum1p. (B) Activation of Ime2p by Ime1p causes inhibition of Sum1p by Ime2p allowing Ime1p to induce low NDT80 expression. (C) Newly synthesized Ndt80p autoactivates its own expression at high levels. (D) Ndt80 upregulates expression of middle genes (After Pak \& Segall, 2002; Kassir et al., 2003; Govin \& Berger, 2009). 

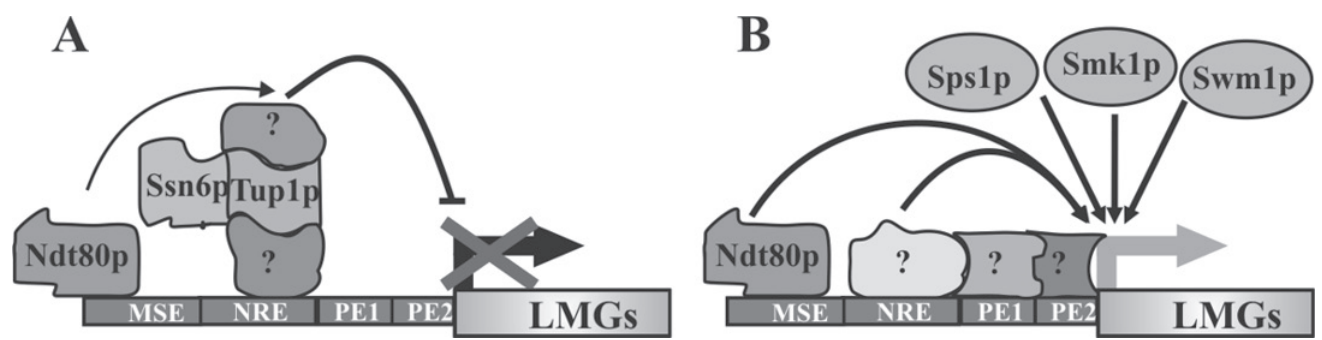

Figure 7. Transcriptional regulation of late genes

(A) During middle stages of sporulation, transcriptional activator Ndt80p binds to promoters of middle-late genes. However, their expression is inhibited by repressor factors binding to Negative Response Elements (NREs). (B) In later stages of sporulation, an unknown activating factor binds to NRE and to two positive elements (PE1 and PE2) and activates expression of middle-late genes. Full expression of middle-late and late genes requires MAPK cascade components Sps1p and Smk1p, and APC complex subunit Swm1p (After Friesen et al., 1997; Vershon \& Pierce, 2000).

ond group, termed late genes, consists of only five genes whose products are engaged in spore maturation (Chu et al., 1998; Vershon \& Pierce, 2000).

Spore formation comprises building of the prospore membrane and the spore wall. The prospore membrane (PSM) is initially formed on the outer plaque of the SPB during the middle stages of sporulation, and at the time of nuclear division it extends to engulf the nuclear lobe by vesicle addition. Vesicular transport plays a critical role in this process (Neiman, 1998; Whitacre et al., 2001; Morischita \& Engebrecht, 2005; Morishita et al., 2007). When the prospore membrane surrounds the nucleus, changes in organelle structure occur (Chu et al., 1998). At the termination of meiosis II, each PSM closes off so that each haploid nucleus becomes encapsulated, together with the cytoplasmic material and organelles, within a double prospore membrane. Between the two layers of the PSMs, the spore wall is assembled de novo (reviewed Kupiec et al., 1997; Neiman, 2005). The mature spore wall consists of four layers in the order from inside to outside: mannan, $\beta-1,3$-glucan, chitosan, and dityrosine. The two outer layers ensure the resistance of spores to environmental factors. The four spores are connected by interspore chitosan bridges and are enclosed inside the ascus, which derives its plasma membrane and cell wall from the respective mother cell's components.

While the regulation of the early and middle sporulation-specific genes has been thoroughly examined, that of the late genes is still poorly understood. Many genes of the middle-late subclass contain a middle sporulation-like element (MSE) and a negative regulatory element (NRE), which contribute to repression in growing cells and to activation in sporulation conditions (Friesen et al., 1997; Vershon \& Pierce, 2000). Despite the presence of the MSE site, these genes are expressed later than the middle sporulation genes, which is due to the NRE element that likely prevents expression during the middle stages of sporulation (Vershon \& Pierce, 2000; Fig. 7A). For the high levels of transcription observed for the middle-late genes in sporulating cells, two additional positive sites are required. One is located between the NRE site and the TATA box, the other is located near the transcription start site (Friesen et al., 1997). The factors that bind to the regulatory sites within the promoters of the middle-late genes and the signals that promote their transcription are unknown. However, several factors required for full expression of these genes have been identified (Vershon \& Pierce, 2000; Fig. 7B). One of them is the sporulation-specific mitogen-activated protein kinase (MAPK) Smk1p. Unlike other MAP ki- nases, transcription of $S M K 1$ is activated by the CDK activating kinase Cak1p (Wagner et al., 1997; Schaber et al., 2002) and is regulated via the meiosis-specific activator of the APC complex Ama1p (McDonald et al., 2009). Regulation through the APC complex plays a role in coupling the completion of meiotic division to spore formation (Oelschlaegel et al., 2005; Penkner et al., 2005). Expression of Smk1p is also controlled by the RAS/cAMP pathway (McDonald et al., 2009), suggesting that nutritional signals regulate both early stages of meiosis and spore formation. Another factor that is required for the expression of middle-late genes is Ssp1p, also a component of the sporulation specific MAPK cascade. However, Ssp1p and Sm$\mathrm{k} 1 \mathrm{p}$ do not function in a linear cascade (Engebrecht, 2003). Ssp1p regulates trafficking of enzymes that are required for the synthesis of the spore wall (Iwamoto et al., 2005). Activation of middle-late sporulation genes also depends on one of the subunits of the APC complex, Swm1p, but this protein acts independently of the Smk1p-Ssp1p MAP kinase cascade (Ufano et al., 1999).

The transcription of the second subclass of late sporulation-specific genes, similarly to the transcription of many middle-late genes, is up-regulated by the Smk1pSps1p kinase cascade and by Swm1p (Vershon \& Pierce, 2000; Engebrecht, 2003). However, none of these genes contain an MSE site (Vershon \& Pierce, 2000). The delay in their induction, compared to that of the middlelate genes, may result from the action of some additional transcriptional regulators or regulatory elements specific to this small group of genes.

\section{CONCLUDING REMARKS}

Sporulation - yeast gametogenesis - is in many respects similar to gametogenesis in mammalian cells. Therefore, it has been subject to comprehensive research for many years. It has proven a suitable model for uncovering the genetic architecture of the meiotic process, for genome-wide studies of the control of gene expression during cell differentiation, as well as for investigating the action of signaling pathways. Data derived from both traditional and genomic-scale genetic screens aiming at the identification of cellular processes that are important for sporulation indicates that the majority of genes critical for meiosis and spore formation encode proteins involved in general cellular processes. These genes are engaged in carbon utilization, autophagy, vacuole targeting, general transcription, and vesicle transport. Significant progress has been made in 
understanding how the signaling networks coordinate the differentiation program in yeast but our knowledge is still incomplete.

\section{REFERENCES}

Anderson SF, Steber CM, Esposito RE, Coleman JE (1995) UME6, a negative regulator of meiosis in Saccharomyces cerevisiae, contains a C-terminal Zn2Cys6 binuclear cluster that binds the URS1 DNA sequence in a zinc-dependent manner. Protein Sci 4: 1832-1843.

Benjamin KR, Zhang C, Shokat KM, Herskowitz I (2003) Control of landmark events in meiosis by the CDK Cdc28 and the meiosisspecific kinase Ime2. Genes Dev 17: 1524-1539.

Blumental-Perry A, Li W, Simchen G, Mitchell AP (2002) Repression and activation domains of Rme1p structurally overlap, but differ in genetic requirements. Mol Biol Cell 13: 1709-1721.

Bolte M, Steigemann P, Braus GH, Inniger S (2002) Inhibition of APC-mediated proteolysis by the meiosis-specific protein kinase Ime2. Proc Natl Acad Sci USA 99: 4385-4390

Bowdish KS, Yuan HE, Mitchell AP (1995) Positive control of yeast meiotic genes by the negative regulator UME6. Mol Cell Biol 15: 2955-2961.

Burgess SM, Ajimura M, Kleckner N (1999) GCN5-dependent histone $\mathrm{H} 3$ acetylation and RPD3-dependent histone $\mathrm{H} 4$ deacetylation have distinct, opposing effects on IME2 transcription, during meiosis and during vegetative growth, in budding yeast. Proc Natl Acad Sci USA 96: 6835-6840.

Chu S, DeRisi J, Eisen M, Mulholland J, Botstein D, Brown PO, Herskowitz I (1998) The transcriptional program of sporulation in budding yeast. Science 282: 699-705.

Chu S, Herskowitz I (1998) Gametogenesis in yeast is regulated by a transcriptional cascade dependent on Ndt80. Mol Cell 1: 685-696.

Clancy MJ, Shambaugh1 ME, Timpte CS, Bokar JA (2002) Induction of sporulation in Saccharomyces cerevisiae leads to the formation of N6-methyladenosine in mRNA: a potential mechanism for the activity of the IME4 gene. Nucleic Acids Res 30: 4509-4518.

Colomina N, Gari E, Gallego C, Herrero E, Aldea M (1999) G1 cyclins block the Ime1 pathway to make mitosis and meiosis incompatible in budding yeast. EMBO J 18: 320-329.

Cooper KF, Strich R (2002) Saccharomyces cerevisiae C-type cyclin Ume3p/Srb11p is required for efficient induction and execution of meiotic development. Eukaryot Cell 1: 66-74.

Covitz PA, Herskowitz I, Mitchell AP (1991) The yeast RME1 gene encodes a putative zinc finger protein that is directly repressed by al-a2. Genes Dev 5: 1982-1989.

Covitz PA, Mitchell AP (1993) Repression by the yeast meiotic inhibitor RME1. Genes Dev 7: 1598-1608.

Engebrecht J (2003) Cell signaling in yeast sporulation. Biochem Biophys Res Commun 306: 325-328.

Esposito RE (2006) Meiosis and spore development, pp 157-192. Cold Spring Harbor Laboratory Press, Cold Spring Harbor, NY.

Esposito RE, Klapholz S (1981) Meiosis and ascospore development. In The molecular biology of the yeast Saccharomyces: Life cycle and inheritance. Strathern et al., eds, p 211-287. Cold Spring Harbor Laboratory, $\mathrm{CSH}, \mathrm{NY}$.

Fazzio TG, Kooperberg C, Goldmark JP, Neal C, Basom R, Delrow J, Tsukiyama T (2001) Widespread collaboration of Isw2 and Sin3Rpd3 chromatin remodeling complexes in transcriptional repression. Mol Cell Biol 21: 6450-6460.

Friedlander G, Joseph-Strauss D, Carmi M, Zenvirth D, Simchen G, Barkai N (2006) Modulation of the transcription regulatory program in yeast cells committed to sporulation. Genome Biol 7: R20.

Friesen H, Hepworth SR, Segall J (1997) An Ssn6-Tup1-dependent negative regulatory element controls sporulation-specific expression of DIT1 and DIT2 in Saccharomyces cerevisiae. Mol Cell Biol 17: 123-134.

Garreau H, Hasan RN, Renault G, Estruch F, Boy-Marcotte E, Jacquet M (2000) Hyperphosphorylation of Msn2p and Msn4p in response to heat shock and the diauxic shift is inhibited by cAMP in Saccharomyces cerevisiae. Microbiology 146: 2113-2120.

Goldmark JP, Fazzio TG, Estep PW, Church GM, Tsukiyama T (2000) The Isw2 chromatin remodeling complex represses early meiotic genes upon recruitment by Ume6p. Cell 103: 423-433.

Govin J, Berger SL (2009) Genome reprogramming during sporulation. Int J Dev Biol 53: 425-432.

Guttmann-Raviv N, Martin S, Kassir Y (2002) Ime2, a meiosis-specific kinase in yeast, is required for destabilization of its transcriptional activator, Ime1. Mol Cell Biol 22: 2047-2056.

Hayashi M, Ohkuni K, Yamashita I (1998) Control of division arrest and entry into meiosis by extracellular alkalisation in Saccharomyces cerevisiae. Yeast 14: 905-913.

Hepworth SR, Friesen H, Segall J (1998) NDT80 and the meiotic recombination checkpoint regulate expression of middle sporulationspecific genes in Saccharomyces cerevisiae. Mol Cell Biol 18: 5750-5761.
Herskowitz I, Rine J, Strathern JN (1992) Mating-type determination and mating type interconversion in Saccharomyces cerevisiae. In The molecular and cellular biology of the yeast Saccharomyces: gene expression. Jones EW, Pringle JR, Broach JR, eds, vol 2, pp 583-656. Cold Spring Harbor Laboratory Press, New York.

Hirschberg J, Simchen G (1977) Commitment to the mitotic cell cycle in yeast in relation to meiosis. Exp Cell Res 105: 245-252.

Hongay CF, Grisafi PL, Galitski T, Fink GR (2006) Antisense transcription controls cell fate in Saccharomyces cerevisiae. Cell 127: 735745 .

Honigberg SM, Lee RH (1998) Snf1 kinase connects nutritional pathways controlling meiosis in Saccharomyces cerevisiae. Mol Cell Biol 18: 4548-4555.

Honigberg SM, Purnapatre K (2003) Signal pathway integration in the switch from the mitotic cell cycle to meiosis in yeast. I Cell Sci 116: 2137-2147.

Inai T, Yukawa M, Tsuchiya E (2007) Interplay between chromatin and trans-acting factors on the IME2 promoter upon induction of the gene at the onset of meiosis. Mol Cell Biol 27: 1254-1263.

Iwamoto MA, Fairclough SR, Rudge SA, Engebrecht J (2005) Saccharomyces cerevisiae Sps1p regulates trafficking of enzymes required for spore wall synthesis. Eukaryot Cell 4: 536-544.

Jambhekar A, Amon A (2008) Control of meiosis by respiration. Curr Biol 18: 969-975.

Kadosh D, Struhl K (1998) Targeted recruitment of the Sin3-Rpd3 histone deacetylase complex generates a highly localized domain of repressed chromatin in vivo. Mol Cell Biol 18: 5121-5127.

Kassir Y, Adir N, Boger-Nadjar E, Raviv NG, Rubin-Bejerano I, Sagee S, Shenhar G (2003) Transcriptional regulation of meiosis in budding yeast. Int Rev Cytol 224: 111-171.

Kassir Y, Granot D, Simchen G (1988) IME1, a positive regulator gene of meiosis in S. cerevisiae. Cell 52: 853-862.

Kassir Y, Simchen G (1976) Regulation of mating and meiosis in yeast by the mating-type region. Genetics 82: 187-206.

Kupiec M, Byers B, Esposito RE (1997) Meiosis and sporulation in Saccharomyces cerevisiae. In The molecular and cell biology of the yeast Saccharomyces. Pringle JR, Broach JR, Jones EW eds, pp 889-1036. Cold Spring Harbor Laboratory Press, Cold Spring Harbor, N.Y.

Lamb TM, Mitchell AP (2003) The transcription factor Rim101p governs ion tolerance and cell differentiation by direct repression of the regulatory genes NRG1 and SMP1 in Saccharomyces cerevisiae. Mol Cell Biol 23: 677-686.

Mallory MJ, Cooper KF, Strich R (2007) Meiosis-specific destruction of the Ume6p repressor by the Cdc20-directed APC/C. Mol Cell 27: 951-961.

Matsumoto K, Uno I, Ishikawa T (1983) Initiation of meiosis in yeast mutants defective in adenylate cyclase and cyclic AMP-dependent protein kinase. Cell 32: 417-423.

McCord R, Pierce M, Xie J, Wonkatal S, Mickel C, Vershon AK (2003) Rfm1, a novel tethering factor required to recruit the Hst1 histone deacetylase for repression of middle sporulation genes. Mol Cell Biol 23: 2009-2016.

McDonald CM, Wagner M, Dunham MJ, Shin ME, Ahmed NT, Winter E (2009) The Ras/cAMP pathway and the CDK-like kinase Ime2 regulate the MAPK Smk1 and spore morphogenesis in Saccharomyces cerevisiae. Genetics 181: 511-523.

Mitchell AP (1994) Control of meiotic gene expression in Saccharomyces cerevisiae. Microbiol Rev 58: 56-70.

Mitchell AP, Herskowitz I (1986) Activation of meiosis and sporulation by repression of the RME1 product in yeast. Nature 319: 738-742.

Mizuno T, Nakazawa N, Remgsamrarn P, Kunoh T, Oshima Y, Harashima S (1998) The Tup1-Ssn6 general repressor is involved in repression of IME1 encoding a transcriptional activator of meiosis in Saccharomyces cerevisiae. Curr Genet 33: 239-247.

Moreno-Borchart AC, Knop M (2003) Prospore membrane formation: how budding yeast gets shaped in meiosis. Microbiol Res 158: 83-90.

Morishita M, Engebrecht J (2005) End3p-mediated endocytosis is required for spore wall formation in Saccharomyces cerevisiae. Genetics 170: 1561-1574.

Morishita M, Mendonsa R, Wright J, Engebrecht J (2007) Snc1p vSNARE transport to the prospore membrane during yeast sporulation is dependent on endosomal retrieval pathways. Traffic 8: 12311245.

Neiman AM (1998) Prospore membrane formation defines a developmentally regulated branch of the secretory pathway in yeast. $J$ Cell Biol 140: 29-37.

Neiman AM (2005) Ascospore formation in the yeast Saccharomyces cerevisiae. Microbiol Mol Biol Rev 69: 565-584.

Oelschlaegel T, Schwickart M, Matos J, Bogdanova A, Camasses A, Havlis J, Shevchenko A, Zachariae W (2005) The yeast APC/C subunit Mnd2 prevents premature sister chromatid separation triggered by the meiosis-specific APC/C-Ama1. Cell 120: 773-788.

Pak J, Segall J (2002) Regulation of the premiddle and middle phases of expression of the NDT80 gene during sporulation of Saccharomyces cerevisiae. Mol Cell Biol 22: 6417-6429. 
Penkner AM, Prinz S, Ferscha S, Klein F (2005) Mnd2, an essential antagonist of the anaphase-promoting complex during meiotic prophase. Cell 120: 789-801.

Petronczki M, Siomos MF, Nasmyth K (2003) Un ménage à quatre: the molecular biology of chromosome segregation in meiosis. Cell 112: $423-440$.

Pierce M, Benjamin KR, Montano SP, Georgiadis MM, Winter E, Vershon AK (2003) Sum1 and Ndt80 proteins compete for binding to middle sporulation element sequences that control meiotic gene expression. Mol Biol Cell 23: 4814-4825.

Primig M, Williams RM, Winzeler EA, Tevzadze GG, Conway AR, Hwang SY, Davis RW, Esposito RE (2000) The core meiotic transcriptome in budding yeasts. Nat Genet 26: 415-423.

Pnueli L, Edry I, Cohen M, Kassir Y (2004) Glucose and nitrogen regulate the switch from histone deacetylation to acetylation for expression of early meiosis-specific genes in budding Yeast Mol Cell Biol 24: 5197-5208.

Rubin-Bejerano I, Mandel S, Robzyk K, Kassir Y (1996) Induction of meiosis in Saccharomyces cerevisiae depends on conversion of the transcriptional represssor Ume6 to a positive regulator by its regulated association with the transcriptional activator Ime1. Mol Cell Biol 16: 2518-2526.

Rubin-Bejerano I, Sagee S, Friedman O, Pnueli L, Kassir Y (2004) The In vivo activity of Ime1, the key transcriptional activator of meiosis-specific genes in Saccharomyces cerevisiae, is inhibited by the cyclic $\mathrm{AMP} /$ protein kinase a signal pathway through the glycogen synthase kinase 3- $\beta$ homolog Rim11. Mol Cell Biol 24: 6967-6979.

Sagee S, Sherman A, Shenhar G, Robzyk K, Ben-Doy N, Simchen G, Kassir Y (1998) Multiple and distinct activation and repression sequences mediate the regulated transcription of IME1, a transcriptional activator of meiosis-specific genes in Saccharomyces cerevisiae. Mol Cell Biol 18: 1985-1995.

Santangelo GM (2006) Glucose signaling in Saccharomyces cerevisiae. Microbiol Mol Biol Rev 70: 253-282.

Schaber M, Lindgren A, Schindler K, Bungard D, Kaldis P (2002) CAK1 promotes meiosis and spore formation in Saccharomyces cerevisiae in a CDC28-independent fashion. Mol Cell Biol 22: 57-68.

Schlecht U, Erb I, Demougin P, Robine N, Borde V, van Nimwegen E, Nicolas A, Primig M (2008) Genome-wide expression profiling, in vivo DNA binding analysis, and probabilistic motif prediction reveal novel Abf1 target genes during fermentation, respiration, and sporulation in yeast. Mol Cell Biol 19: 2193-2207.

Shah JC, Clancy MJ (1992) IME4, a gene that mediates MAT and nutritional control of meiosis in Saccharomyces cerevisiae. Mol Cell Biol 12: 1078-1086.

Shenhar G, Kassir Y (2001) A positive regulator of mitosis, Sok2, functions as a negative regulator of meiosis in Saccharomyces cerevisiae. Mol Cell Biol 21: 1603-1612.

Shimizu M, Li W, Shindo H, Mitchell AP (1997) Transcriptional repression at a distance through exclusion of activator binding in vivo. Proc Natl Acad Sci USA 94: 790-795.

Simchen G (2009) Commitment to meiosis: what determines the mode of division in budding yeast? Bioessays 31: 169-177.

Simchen G, Piñon R, Salts Y (1972) Sporulation in Saccharomyces cerevisiae: premeiotic DNA synthesis, readiness and commitment. Exp Cell Res 75: 207-218.

Smith HE, Driscoll SE, Sia RA, Yuan HE, Mitchell AP (1993) Genetic evidence for transcriptional activation by the yeast IME1 gene product. Genetics 133: 775-784.

Smith R.L, Johnson AD (2000) Turning genes off by Ssn6-Tup1: a conserved system of transcriptional repression in eukaryotes. Trends Biochem Sci 25: 325-330.
Smits, GJ, van den Ende H, Klis FM (2001) Differential regulation of cell wall biogenesis during growth and development in yeast. Microbiology 147: 781-794.

Steber CM, Esposito RE, Coleman JE (1995) UME6, a negative regulator of meiosis in Saccharomyces cerevisiae, contains a C-terminal $\mathrm{Zn}$ 2Cys6 binuclear cluster that binds the URS1 DNA sequence in a zinc-dependent manner. Protein Sci 4: 1832-1843.

Strich R, Surosky RT, Steber C, Dubois E, Messenguy F, Esposito RE (1994) UME6 is a key regulator of nitrogen repression and meiotic development. Genes Dev 8: 796-810.

Ufano S, San-Segundo P, del Rey F, Vázquez de Aldana CR (1999) SWM1, a developmentally regulated gene, is required for spore wall assembly in Sacharomyces cerevisiae. Mol Cell Biol 19: 2118-2129.

van Dyk D, Hansson G, Pretorius IS, Bauer FF (2003) Cellular differentiation in response to nutrient availability: the repressor of meiosis, Rme1p, positively regulates invasive growth in Saccharomyces cerevisiae. Genetics 165: 1045-1058.

Vershon AK, Pierce M (2000) Transcriptional regulation of meiosis in yeast. Curr Opin Cell Biol 12: 334-339.

Vidan S, Mitchell AP (1997) Stimulation of yeast meiotic gene expression by the glucose-repressible protein kinase Rim15p. Mol Cell Biol 17: 2688-2697.

Wagner M, Pierce M, Winter E (1997) The CDK-activating kinase CAK1 can dosage suppress sporulation defects of smk1 MAP kinase mutants and is required for spore wall morphogenesis in Saccharomyces cerevisiae. EMBO J 16: 1305-1317.

Washburn BK, Esposito RE (2001) Identification of the Sin3-binding site in Ume6 defines a two-step process for conversion of Ume6 from a transcriptional repressor to an activator in yeast. Mol Cell Biol 21: 2057-2069.

Weber JM, Irlbacher H, Ehrenhofer-Murray AE (2008) Control of replication initiation by the Sum1/Rfm1/Hst1 histone deacetylase. BMC Mol Biol 9: 100.

Whitacre JL, Davis DA, Toenjes KA, Brower SM, Adams EM (2001) Generation of an isogenic collection of yeast actin mutants and identification of three interrelated phenotypes. Genetics 157: 533-543.

Williams RM, Primig M, Washburn BK, Winzeler EA, Bellis M, de Menthie re CS, Davis RW, Esposito RE (2002) The Ume6 regulon coordinates metabolic and meiotic gene expression in yeast. Proc Natl Acad Sci USA 99: 13431-13436.

Xiao Y, Mitchell AP (2000) Shared roles of yeast glycogen synthase kinase 3 family members in nitrogen-responsive phosphorylation of meiotic regulator Ume6p. Mol Cell Biol 20: 5447-5453.

Xie J, Pierce M, Gailus-Durner V, Wagner M, Winter E, Vershon AK (1999) Sum1 and Hst1 repress middle sporulation-specific gene expression during mitosis in Saccharomyces cerevisiae. EMBO J 18: 64486454.

Yoshida M, Kawaguchi H, Sakata Y, Kominami K, Hirano M, Shima H, Akada R, Yamashita I (1990) Initiation of meiosis and sporulation in Saccharomyces cerevisiae requires a novel protein kinase homologue. Mol Gen Genet 221: 176-186.

Zaman S, Lippman SI, Zhao X, Broach JR (2008) How Saccharomyces responds to nutrients. Annu Rev Genet 42: 27-81.

Zenvirth D, Loidl J, Klein S, Arbel A, Shemesh R, Simchen G (1997) Switching yeast from meiosis to mitosis: double-strand break repair, recombination and synaptonemal complex. Genes Cells 2: 487-498.

Zhang Z, Reese JC (2004) Redundant mechanisms are used by Ssn6Tup1 in repressing chromosomal gene transcription in Saccharomyces cerevisiae. J Biol Chem 279: 39240-39250. 